\title{
Video Article \\ Serum Free Production of Three-dimensional Human Hepatospheres from Pluripotent Stem Cells
}

\author{
Balta Lucendo-Villarin ${ }^{1}$, Hassan Rashidi ${ }^{1,2}$, Sharmin Alhaque ${ }^{1,3}$, Lena Fischer ${ }^{1,4}$, Jose Meseguer-Ripolles ${ }^{1}$, Yu Wang $^{1}$, Cliona O'Farrelly ${ }^{4}$, \\ Michael Themis ${ }^{3}$, David C. Hay ${ }^{1}$ \\ ${ }^{1}$ MRC Centre for Regenerative Medicine, University of Edinburgh \\ ${ }^{2}$ UCL Great Ormond Street Institute of Child Health, University College London \\ ${ }^{3}$ Division of Biosciences, Department of Life Sciences, College of Health and Life Sciences, Brunel University London \\ ${ }^{4}$ School of Biochemistry and Immunology, Trinity Biomedical Sciences Institute, Trinity College Dublin
}

Correspondence to: David C. Hay at davehay@talktalk.net

URL: https://www.jove.com/video/59965

DOI: doi:10.3791/59965

Keywords: Developmental Biology, Issue 149, pluripotent stem cells, three-dimensional culture, hepatospheres, drug metabolism and protein secretion, stable cell phenotype, defined culture system

Date Published: $7 / 20 / 2019$

Citation: Lucendo-Villarin, B., Rashidi, H., Alhaque, S., Fischer, L., Meseguer-Ripolles, J., Wang, Y., O'Farrelly, C., Themis, M., Hay, D.C. Serum Free Production of Three-dimensional Human Hepatospheres from Pluripotent Stem Cells. J. Vis. Exp. (149), e59965, doi:10.3791/59965 (2019).

\section{Abstract}

The development of renewable sources of liver tissue is required to improve cell-based modelling, and develop human tissue for transplantation. Human embryonic stem cells (hESCs) and human induced pluripotent stem cells (hiPSCs) represent promising sources of human liver spheres. We have developed a serum free and defined method of cellular differentiation to generate three-dimensional human liver spheres formed from human pluripotent stem cells. A potential limitation of the technology is the production of dense spheres with dead material inside. In order to circumvent this, we have employed agarose microwell technology at defined cell densities to control the size of the 3D spheres, preventing the generation of apoptotic and/or necrotic cores. Notably, the spheres generated by our approach display liver function and stable phenotype, representing a valuable resource for basic and applied scientific research. We believe that our approach could be used as a platform technology to develop further tissues to model and treat human disease and in the future may permit the generation of human tissue with complex tissue architecture.

\section{Video Link}

The video component of this article can be found at https://www.jove.com/video/59965/

\section{Introduction}

The ability of human pluripotent stem cells (hPSCs) to self-renew, whilst retaining pluripotency, provides an opportunity to produce human cell types and tissues on demand. hPSCs have been efficiently differentiated into hepatocyte-like cells (HLCs) using two-dimensional (2D) adherent culture systems $1,2,3,4,5,6,7,8,9,10$. These systems have been used to successfully model monogenic disease, virus lifecycle, drug induced liver injury (DILI), fetal exposure to toxins and non-alcoholic fatty liver disease (NAFLD) $)^{11,12,13,14,15}$. However, these models do possess some drawbacks, which limit their routine use. Those include fetal marker expression, unstable phenotype and poor tissue architecture ${ }^{16,17,18,19}$, which could also limit extrapolation to organ function in vivo.

To overcome these limitations, three-dimensional (3D) differentiation platforms have been developed to mimic in vivo tissue architecture. Although enabling, those approaches rely on the use of animal derived products and matrices to drive tissue genesis ${ }^{20,21,22}$, limiting scale-up and widespread application.

Here, we detail procedures to generate large quantities of 3D hepatospheres from hPSCs using defined materials and cell self-assembly. Notably, the tissue generated by our procedure remains functional for more than one year in cell culture and is capable of supporting liver function in vivo ${ }^{23}$.

In summary, our defined differentiation approach allows the generation of stable human hepatospheres from both human embryonic stem cells (hESCs) and induced pluripotent stem cells (iPSCs). We believe the described procedure represents a significant breakthrough in the generation of 3D hepatospheres for basic and applied scientific research. 


\section{Preparation of Agarose Microplate Molds}

NOTE: Media used for these experiments must be sterile and at room temperature (RT) for cell culture.

1. Prepare $2 \%$ agarose molds.

1. Dissolve $2 \mathrm{~g}$ of low melting temperature agarose into $100 \mathrm{~mL}$ of sterilized distilled water. Carefully heat in a microwave with interval shaking to dissolve completely.

2. Add $520 \mu \mathrm{L}$ of melted agarose to a 256 -well format mold and leave to solidify.

3. Transfer each agarose microplate into a single well of a 12-well plate.

4. Add $1.5 \mathrm{~mL}$ of $1 \times$ Dulbecco's phosphate-buffered saline (DPBS) with $\mathrm{Ca}^{2+} / \mathrm{Mg}^{2+}$ to each well and remove the air bubbles from the microwells by gently pipetting up and down several times using a P1000 pipette tip. This is performed to ensure uniform cell seeding. NOTE: Agarose microplates can be stored for up to 6 months at $4{ }^{\circ} \mathrm{C}$ in $1 \times$ DPBS.

\section{Seeding Human Pluripotent Stem Cells into Agarose Microwell Plates}

\section{Preparation of cell suspension}

1. Aspirate the medium from an undifferentiated culture of hPSCs as previously described ${ }^{8}$. NOTE: hPSCs are cultured on LN-521 in mTeSR1 with the medium changed every $24 \mathrm{~h}$, and passaged regularly once the cells reach $75 \%$ to $85 \%$ of confluency as previously described ${ }^{8}$.

2. Rinse the cells with $5 \mathrm{~mL}$ of RT $1 \times$ DPBS without $\mathrm{Ca}^{2+} / \mathrm{Mg}^{2+}$ and remove the buffer.

3. Add $5 \mathrm{~mL}$ of $1 \mathrm{x}$ cell dissociation reagent (Table of Materials) to the cells and allow cell dissociation by incubating cells at $37^{\circ} \mathrm{C}$ for $6-8$ $\min$.

NOTE: To stop the reaction, examine cell detachment under the microscope. The cells should be partially detached from the plate. Extend the incubation for an extra 1-2 min if longer time is required.

4. Stop the reaction by removing the cell dissociation reagent and add $5 \mathrm{~mL}$ of fresh $\mathrm{mTeSR} 1$ medium supplemented with $10 \mu \mathrm{M}$ Rhoassociated kinase (ROCK) inhibitor Y27632 to the cells. Dissociate cells by pipetting up and down several times by using a P1000 pipette tip.

5. Count the viable cells using a hemocytometer and trypan blue staining exclusion. Following this, prepare the cell suspension at the required concentration.

6. Calculate the total number of cells needed. For $3 \mathrm{D}$ hepatosphere differentiation, seed $3.84 \times 10^{5}$ cells per agarose microplate to generate spheroids with 100-150 $\mu \mathrm{m}$ in diameter.

7. Transfer the desired number of cells into a sterile $15 \mathrm{~mL}$ or $50 \mathrm{~mL}$ centrifuge tube and centrifuge the tube at $200 \times g$ for $5 \mathrm{~min}$ at $\mathrm{RT}$ to pellet the cells.

8. Aspirate and discard the supernatant and resuspend cells in mTeSR1 medium plus $10 \mu \mathrm{M}$ ROCK inhibitor Y27632. Dilute the cell pellet in the appropriate volume of medium to a final concentration of $2.1 \times 10^{6} \mathrm{cells} / \mathrm{mL}$.

2. Seeding the cells to the prepared agarose microplates

NOTE: If using fridge-stored agarose microplates, place them in the cell incubator at $37^{\circ} \mathrm{C}$ for at least an hour prior to use and aspirate the $1 \times$ DPBS from the well before cell seeding.

1. Add $190 \mu \mathrm{L}$ of the cell suspension into the agarose microwell.

2. After seeding, return the plates to the cell incubator at $37{ }^{\circ} \mathrm{C}$ and $5 \% \mathrm{CO}_{2}$ for $2 \mathrm{~h}$ to allow the cells to settle.

3. After $2 \mathrm{~h}$, add $1 \mathrm{~mL}$ of fresh and warm mTeSR1 medium supplemented with $10 \mu \mathrm{M}$ ROCK inhibitor Y27632 to each well.

4. Return the plates to the cell incubator at $37^{\circ} \mathrm{C}$ and $5 \% \mathrm{CO}_{2}$ for $24 \mathrm{~h}$ and examine the formation of spheres the next day to allow the cells to attach.

\section{Differentiating hPSCs to 3D Hepatospheres on Agarose Microwells}

1. Preparation of poly 2-hydroxyethyl methacrylate (poly-HEMA) coated wells

1. Dissolve $2 \mathrm{~g}$ of poly-HEMA in $100 \mathrm{~mL}$ of $95 \%$ ethanol. Stir the solution overnight using a hot plate at $55^{\circ} \mathrm{C}$. Add $250 \mu \mathrm{L}$ of poly-HEMA solution per well of a 24 -well plate and dry overnight at $60^{\circ} \mathrm{C}$ using an oven.

2. Preparation of the differentiation medium

1. Prepare a $1,000 x$ stock solution of human activin $A$ by dissolving human activin $A$ lyophilized protein in sterile $0.2 \%$ bovine serum albumin (BSA)/DPBS to a final concentration of $100 \mu \mathrm{g} / \mathrm{mL}$. Store at $-20^{\circ} \mathrm{C}$ in small aliquots. Use at $1: 1,000$.

2. Prepare a $1,000 x$ stock solution of Wnt3a by dissolving mouse Wnt3a lyophilized protein in sterile $0.2 \%$ BSA/DPBS to a final concentration of $10 \mu \mathrm{g} / \mathrm{mL}$. Store at $-20^{\circ} \mathrm{C}$ in small aliquots. Use at 1:200.

3. Prepare a 1,000x stock solution of human hepatocyte growth factor (HGF) by dissolving human HGF lyophilized protein in sterile $0.2 \%$ BSA/DPBS to a final concentration of $10 \mu \mathrm{g} / \mathrm{mL}$. Store at $-20^{\circ} \mathrm{C}$ in small aliquots. Use at $1: 1,000$.

4. Prepare a $1,000 x$ stock solution of oncostatin M (OSM) by dissolving OSM in sterile $0.2 \%$ BSA/DPBS to a final concentration of $20 \mu g /$ $\mathrm{mL}$. Store at $-20^{\circ} \mathrm{C}$ in small aliquots. Use at $1: 1,000$.

5. Prepare a $1000 x$ stock solution of epithelial growth factor (EGF) by dissolving the lyophilized protein in sterile $0.2 \%$ BSA/DPBS to a final concentration of $10 \mu \mathrm{g} / \mathrm{mL}$. Store at $-20^{\circ} \mathrm{C}$ in small aliquots. Use at 1:1,000. 
6. Prepare a $1,000 x$ stock solution of basic fibroblast growth factor (bFGF) by dissolving the lyophilized protein in sterile $0.2 \%$ BSA/DPBS to a final concentration of $10 \mu \mathrm{g} / \mathrm{mL}$. Store at $-20^{\circ} \mathrm{C}$ in small aliquots. Use at $1: 1,000$.

7. Prepare a $1,000 x$ stock solution of vascular endothelial growth factor (VEGF) by dissolving the lyophilized protein in $0.2 \%$ BSA/DPBS to a final concentration of $10 \mu \mathrm{g} / \mathrm{mL}$. Store at $-20^{\circ} \mathrm{C}$ in small aliquots. Use at $1: 1,000$.

8. Make endoderm differentiation medium consisting of Roswell Park Memorial Institute 1640 (RPMI 1640) basal medium supplemented with $2 \%$ B27 supplement (50x, without insulin), and $1 \%$ penicillin/streptomycin (final concentrations: $100 \mathrm{IU} / \mathrm{mL}$ and $100 \mu \mathrm{g} / \mathrm{mL}$, respectively). Unless indicated, at each medium change, supplement the required volume with Wnt3a and activin A at a final concentration of $50 \mathrm{ng} / \mathrm{mL}$ and $100 \mathrm{ng} / \mathrm{mL}$, respectively.

NOTE: Store at $4{ }^{\circ} \mathrm{C}$ and use within two weeks.

9. Make hepatoblast differentiation medium consisting of knockout Dulbecco's modified Eagle medium (KO-DMEM) with $20 \%$ knockout serum replacement (KOSR) and supplemented with $0.5 \%$ of an alternative supplement to L-glutamine, $1 \%$ non-essential amino acids (NEAA), $0.1 \mathrm{mM}$ beta-mercaptoethanol, $1 \%$ dimethyl sulfoxide (DMSO), and 1\% penicillin/streptomycin (final concentrations at $100 \mathrm{IU} /$ $\mathrm{mL}$ and $100 \mu \mathrm{g} / \mathrm{mL}$, respectively). Filter under vacuum.

NOTE: Store at $4{ }^{\circ} \mathrm{C}$ and use within two weeks.

10. Make hepatocyte maturation medium consisting of hepatocyte medium supplemented with $1 \%$ of an alternative supplement to Lglutamine, $10 \mu \mathrm{M}$ hydrocortisone 21-hemisuccinate sodium salt (HCC), $1 \%$ penicillin/streptomycin (final concentrations at $100 \mathrm{lU} / \mathrm{mL}$ and $100 \mu \mathrm{g} / \mathrm{mL}$, respectively). For each medium change, supplement the required volume with OSM and HGF (final concentrations at $20 \mathrm{ng} / \mathrm{mL}$ and $10 \mathrm{ng} / \mathrm{mL}$, respectively).

NOTE: Store the stock at $4{ }^{\circ} \mathrm{C}$ and use within two weeks.

11. Make hepatocyte maintenance medium consisting of William's E medium supplemented with $10 \%$ knockout serum replacement, consisting of $1 \%$ of an alternative supplement to L-glutamine, $1 \%$ penicillin/streptomycin (final concentrations at $100 \mathrm{IU} / \mathrm{mL}$ and $100 \mu \mathrm{g} /$ $\mathrm{mL}$, respectively). For each medium change, supplement the required volume with HGF, EGF, bFGF and VEGF (final concentration of each growth factor at $10 \mathrm{ng} / \mathrm{mL}$ ).

NOTE: Store the stock at $4{ }^{\circ} \mathrm{C}$ and use within two weeks.

3. Check hepatosphere formation $24 \mathrm{~h}$ post seeding and initiate hepatocyte differentiation. Carefully remove the mTeSR 1 medium and replace it with $1 \mathrm{~mL}$ of fresh endoderm differentiation medium supplemented with $100 \mathrm{ng} / \mathrm{mL}$ activin $\mathrm{A}$ and $50 \mathrm{ng} / \mathrm{mL}$ Wnt $3 a$.

4. Change supplemented endoderm priming medium every $24 \mathrm{~h}$ for 3 days for hESCs. When working with hiPSCs, extend this stage for a further 2 days supplementing the media with activin $\mathrm{A}(100 \mathrm{ng} / \mathrm{mL})$ alone.

5. Following definitive endoderm induction, switch to hepatoblast differentiation medium for hepatoblast specification for 5 days replacing the medium every 2 days and perform the last change on the last day of the hepatoblast specification.

6. Transfer hepatospheres into the poly-HEMA coated wells.

1. Wash the cells once with hepatocyte maturation medium without supplements after removing KSR/DMSO medium and add $1 \mathrm{~mL}$ of hepatocyte maturation medium supplemented with $10 \mathrm{ng} / \mathrm{mL}$ HGF and $20 \mathrm{ng} / \mathrm{mL} \mathrm{OSM}$.

2. Using a P1000 pipette, lift up the hepatospheres from the agarose microplate by pipetting up and down the solution several times.

3. Transfer the medium containing the hepatospheres to a poly-HEMA coated well.

4. Wash the agarose microplate using $1 \mathrm{~mL}$ of hepatocyte maturation medium supplemented with $10 \mathrm{ng} / \mathrm{mL} \mathrm{HGF}$ and $20 \mathrm{ng} / \mathrm{mL}$ OSM and transfer the medium to the poly-HEMA coated well.

5. Repeat step 3.6.4 as many times as possible in order to transfer all the hepatospheres from the agarose microplate. NOTE: It is critical to carefully pipette up and down the solution containing the hepatospheres to avoid damaging them.

7. Carefully aspirate excess medium without removing hepatospheres by using a P100 pipette until $\sim 1$ mL of medium containing the hepatospheres remains in the poly-HEMA coated well.

8. Change the medium every $48 \mathrm{~h}$ for 12 days.

9. At day $\mathbf{2 0}$ when working with hESCs or day 22 if working with hiPSCs, switch the medium to hepatocyte maintenance medium.

1. Remove hepatocyte maturation medium and wash cells once with hepatocyte maintenance medium without the supplements. Add 1 $\mathrm{mL}$ of hepatocyte maintenance medium supplemented with $10 \mathrm{ng} / \mathrm{mL}$ of HGF, EGF, FGF and VEGF.

10. Change the medium for fresh hepatocyte maintenance medium every $48 \mathrm{~h}$

\section{Functional Analysis of Long-term Cultured 3D Hepatospheres}

1. Switch to hepatocyte maturation medium supplemented with $10 \mu \mathrm{M} \mathrm{HCC}$, L-glutamine, $1 \%$ penicillin/streptomycin (final concentrations at 100 $\mathrm{IU} / \mathrm{mL}$ and $100 \mu \mathrm{g} / \mathrm{mL}$, respectively) and $10 \mathrm{ng} / \mathrm{mL}$ HGF $48 \mathrm{~h}$ prior to performing functional analysis.

2. Analyze hepatocyte metabolic function using cytochrome (CYP) P450 assays.

1. Replace medium with $1 \mathrm{~mL}$ of fresh hepatocyte maturation medium supplemented with $50 \mu \mathrm{M}$ luciferin-6'-pentafluoro-benzyl ether (luciferin-PFBE) substrate to detect CYP3A basal activity or $100 \mu \mathrm{M}$ luciferin-methyl ether (luciferin-ME) substrate to detect CYP1A2 basal activity (number of replicates $=3$ ). Use tissue culture media as a negative control.

NOTE: In order to avoid cross-reactivity, it is recommended not to use the same wells containing 3D hepatospheres to test different CYP P450 activities but to perform them in individual wells.

2. Incubate cells for $24 \mathrm{~h}$ at $37^{\circ} \mathrm{C}$.

3. Collect the supernatants using a P100 pipette tip and carry out the assay as per manufacturer's instructions.

4. Measure the relative levels of basal activity and normalize to per mg protein as determined by the bicinchoninic acid assay (BCA).

3. Test serum protein production using enzyme-linked immunosorbent assay (ELISA).

1. Replace medium with $1 \mathrm{~mL}$ of fresh hepatocyte maturation medium supplemented with $10 \mathrm{ng} / \mathrm{mL} \mathrm{HGF}$ and $20 \mathrm{ng} / \mathrm{mL} \mathrm{OSM} \mathrm{(number} \mathrm{of}$ replicates $=3$ ). Use tissue culture media as a negative control.

2. Incubate cells for $24 \mathrm{~h}$ at $37^{\circ} \mathrm{C}$.

3. Collect the supernatant using a P100 pipette tip and measure the relative levels of serum protein production as per manufacturer's instructions. 
4. Normalize to per mg protein as determined by the BCA Assay.

\section{Immunocytochemistry}

1. Preparation of paraffin sections containing hepatospheres.

1. Wash the hepatospheres three times with $1 \times$ DPBS.

2. Fix the hepatospheres with ice-cold methanol for $30 \mathrm{~min}$.

3. Wash three times with $1 \times$ DPBS.

4. Embed the hepatospheres in $300 \mu \mathrm{L}$ of a tempered solution of $2 \%$ agarose dissolved in $\mathrm{H}_{2} \mathrm{O}$ using an empty well of a 24 -well plate as a mold and leave it to solidify for $30 \mathrm{~min}$.

5. Embed the agarose containing hepatospheres in paraffin.

6. Section the paraffin block containing fixed hepatospheres in $4 \mu \mathrm{m}$ thick sections using a microtome.

2. De-waxing and rehydration of the sections.

NOTE: Use fresh solutions whenever it is possible. Do not use solutions that have been on the staining trough for longer than a week.

1. Place sections in a slide rack.

2. Immerse slide rack containing sections in a staining trough containing $300 \mathrm{~mL}$ of xylene for $5 \mathrm{~min}$.

3. Repeat step 5.2.2.

4. Immerse in absolute ethanol for $20 \mathrm{~s}$.

5. Immerse in $95 \%$ ethanol for $20 \mathrm{~s}$.

6. Immerse in $90 \%$ ethanol for $20 \mathrm{~s}$.

7. Immerse in $80 \%$ ethanol for $20 \mathrm{~s}$.

8. Immerse in $70 \%$ ethanol for $20 \mathrm{~s}$.

9. Rehydrate the sections with water for $5 \mathrm{~min}$.

NOTE: Maintain the slides in the same slide rack and move it from one staining trough to the next one. Volume used (generally $\sim 300$ $\mathrm{mL}$ ) depends on the size of the staining trough.

3. Antigen retrieval of paraffin sections containing hepatospheres.

1. Heat de-waxed and rehydrated sections in $1 \times$ Tris-EDTA (TE) pH 9.0 buffer solution for 15 min in a microwave at $800 \mathrm{~W}$.

2. Cool down samples by immersing them in tap water for $5 \mathrm{~min}$.

4. Immunostaining.

1. Incubate slides with blocking solution made of PBS with $0.1 \%$ polysorbate 20 (PBS/T)/10\% BSA for $1 \mathrm{~h}$ at RT.

2. Replace blocking solution with the appropriate primary antibody diluted in $\mathrm{PBS} / \mathrm{T} / 1 \% \mathrm{BSA}$ and incubate at $4{ }^{\circ} \mathrm{C}$ with gentle agitation overnight.

3. Wash cells with PBS/T for 5 min and repeat three times.

4. Incubate with the appropriate secondary antibody diluted in PBS/T/1\% BSA and incubate in the dark at RT for $1 \mathrm{~h}$ with gentle agitation. NOTE: The optimized primary and secondary antibodies are listed in Table of Materials.

5. Wash cells with PBS/T for 5 min and repeat three times.

6. Add 4',6-diamidino-2-phenylindole (DAPI) to the cells according to manufacturer's instructions and place a glass coverslip gently to reduce air bubbles. Keep fixed cells at $4{ }^{\circ} \mathrm{C}$ in the dark. Observe staining under a microscope with appropriate filter and fluorescent lamp.

NOTE: Store plates at $4{ }^{\circ} \mathrm{C}$ in the dark until imaging.

\section{Representative Results}

Three-dimensional aggregates from the embryonic stem cell line (H9) or the induced pluripotent stem cell line (P106) were differentiated towards the hepatocyte lineage using our defined procedure (Figure 1). Pluripotent stem cells were first primed towards definitive endoderm prior to hepatoblast specification. Following this, hepatoblasts were matured into 3D hepatospheres which could be maintained in culture for up to one year $^{23}$.

To study the structure of 3D spheres, 30 day-old hESC- or iPSC-derived spheres were fixed, sectioned and stained to detect the presence of proteins expressed in hepatocytes and mesenchymal cells. Hepatocyte nuclear factor 4 alpha (HNF4a) and the mesenchymal marker vimentin were employed, revealing the presence of an outer layer composed of hepatocyte like cells surrounding a core of mesenchymal cells (Figure 2). We followed these experiments analyzing the expression of proteins expressed in hepatocytes: albumin, CYP3A and E-cadherin. Immunostaining revealed that the expression of these proteins was restricted to the outer layer of the spheres (Figure 3).

Functional analyses of the hepatospheres were performed in day 30 cultures. CYP1A2 and CYP3A are important enzymes within functional hepatocytes. Their activity was assessed using established assays. H9-derived hepatospheres exhibited CYP3A activity of 220,375 \pm 74514 $\mathrm{RLU} / \mathrm{mL} / \mathrm{mg}$ protein and CYP1A2 activity of $732,440 \pm 33,330 \mathrm{RLU} / \mathrm{mL} / \mathrm{mg}$ protein (Figure 4A). CYP3A activity in P106-derived hepatospheres was $132117 \pm 43,391 \mathrm{RLU} / \mathrm{mL} / \mathrm{mg}$ protein and CYP1A2 activity was 409,907 $\pm 121,723 \mathrm{RLU} / \mathrm{mL} / \mathrm{mg}$ protein (Figure 4B). When compared with two batches of human primary hepatocytes, 3D liver spheres displayed respectable levels of CYP activity ${ }^{10}$.

Analysis of the synthesis and secretion of albumin and alpha-fetoprotein (AFP) revealed that H9-derived hepatospheres secreted $683.9 \pm 84$ and $159 \pm 20 \mathrm{ng} / \mathrm{mL} / 24 \mathrm{~h} / \mathrm{mg}$ protein of albumin and alpha-fetoprotein, respectively (Figure 5A). Whereas P106-derived hepatospheres secreted 497 \pm 41 and $756 \pm 24 \mathrm{ng} / \mathrm{mL} / 24 \mathrm{~h} / \mathrm{mg}$ protein of albumin and alpha-fetoprotein, respectively (Figure 5B). 


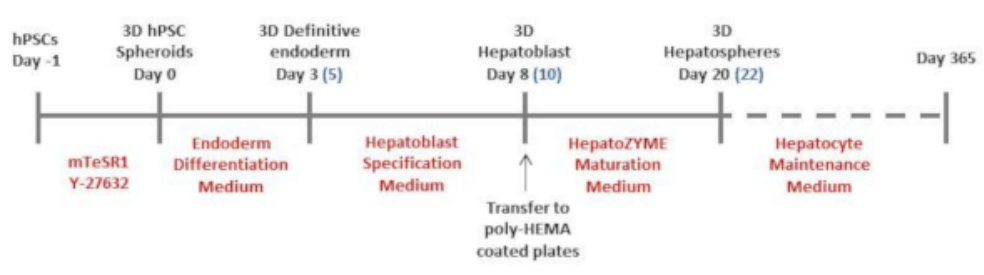

Figure 1: Stepwise differentiation procedure to generate 3D hepatospheres from hESCs. Blue brackets represent days of differentiation for hiPSCs. Please click here to view a larger version of this figure.

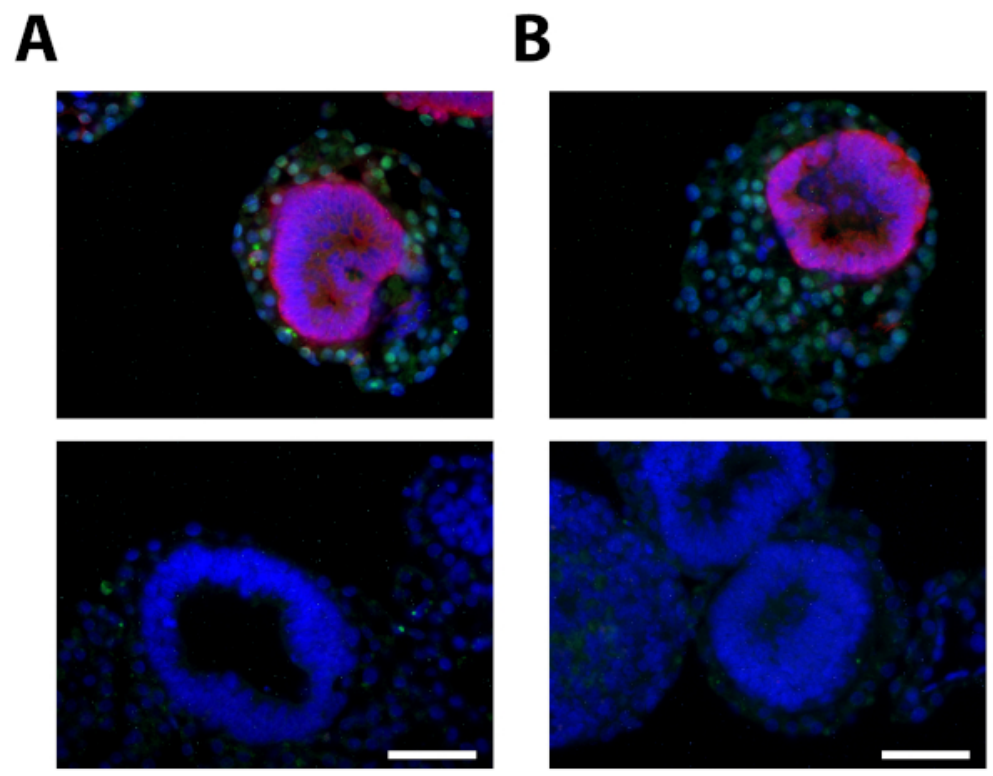

Figure 2: Structural reorganization of 3D hepatospheres. Representative images of the expression of hepatocyte nuclear factor 4 alpha (HNF4a - green) and vimentin (red) in (A) H9-derived 3D hepatospheres and (B) P106-derived 3D hepatospheres and their corresponding immunoglobulin $\mathrm{G}(\mathrm{IgG})$ controls. Scale bars represent $60 \mu \mathrm{m}$. Please click here to view a larger version of this figure. 
A
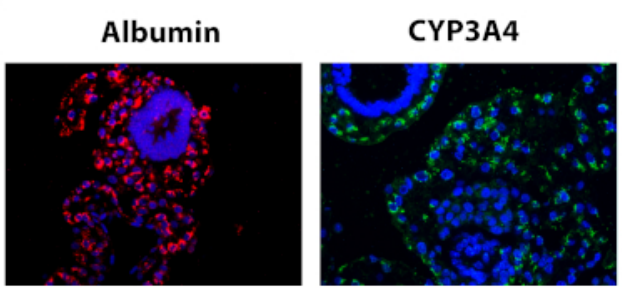

\section{E-Cadherin}
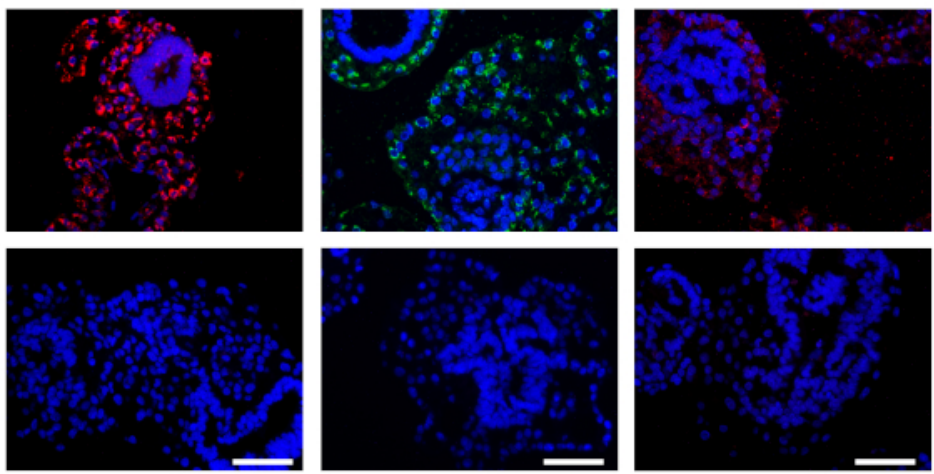

Albumin
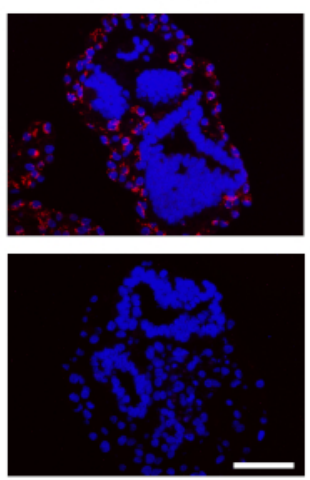

CYP3A4
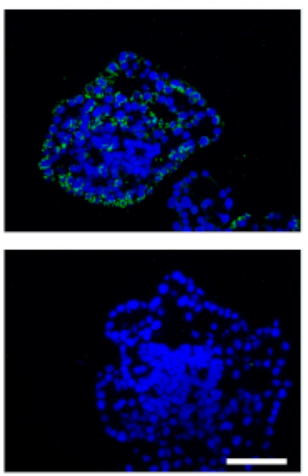

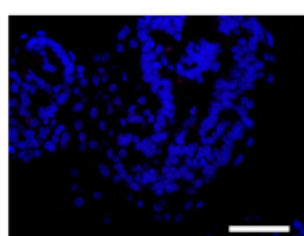

E-Cadherin
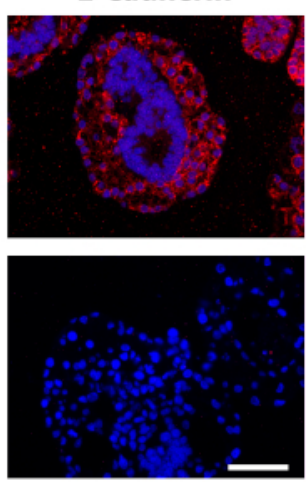

Figure 3: Evaluation of hepatic marker expression in 3D hepatospheres. Representative images of the expression of hepatocyte markers - albumin, CYP3A, E-cadherin and their corresponding IgG controls in (A) H9- and (B) P106-derived 3D hepatospheres. Scale bars $=60 \mu \mathrm{m}$. Please click here to view a larger version of this figure.

H9 - 3D hepatospheres

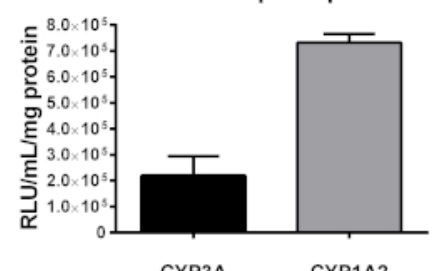

CYP3A

CYP1A2

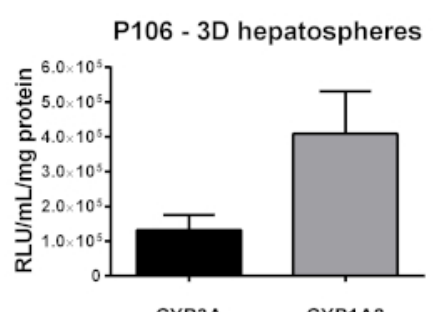

Figure 4: Cytochrome P450 function in 3D hepatospheres. Measurement of the cytochrome P450 $1 \mathrm{~A} 2$ and $3 \mathrm{~A}$ activity in (A) H9-derived 3D hepatospheres and (B) P106-derived 3D hepatospheres. The data represents the mean of three biological replicates, and the error bars represent the standard deviation (SD). Activity is quoted as relative light units (RLU) per $\mathrm{mL}$ per $\mathrm{mg}$ of protein. Please click here to view a larger version of this figure. 

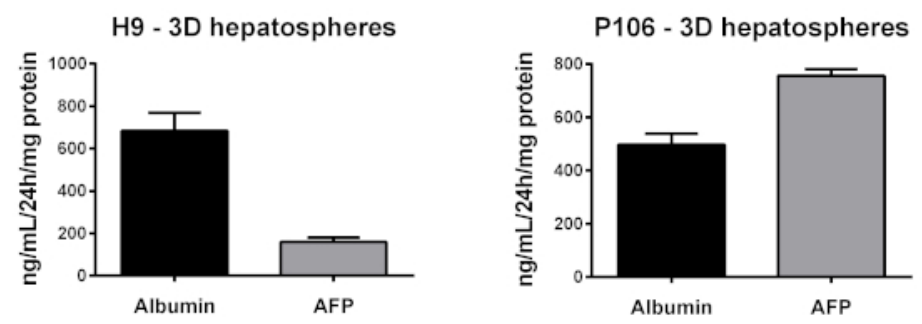

Figure 5: Analysis of hepatosphere protein secretion. The secretion of albumin and alpha-fetoprotein (AFP) was analyzed in (A) H9derived 3D hepatospheres and (B) P106-derived 3D hepatospheres. The data is representative of three biological replicates, and the error bars represent the SD. Secreted protein is quoted as nanograms of protein per $\mathrm{mL}$ per $24 \mathrm{~h}$ per $\mathrm{mg}$ of protein. Please click here to view a larger version of this figure.

\section{Discussion}

The development of defined and xeno-free systems to produce human hepatospheres in 3D is required for both in vitro and in vivo endeavors. At present most hepatocyte differentiation approaches from human pluripotent stem cells are performed in two dimensional adherent cultures. These environments lack many of the environmental cues involved in tissue genesis and homeostasis which include; heterotypic cell interactions, matrix production and remodeling, resulting in poor translation to the in vivo biology ${ }^{18,19}$.

As a result, research has focused on alternative approaches to generate hepatospheres from pluripotent stem cells. A number of 3D studies have advanced the field, but those are reliant on animal products ${ }^{20,22,24}$ to provide support and/or require the use of human tissue ${ }^{21,22}$ which complicates technology scale-up and compromises experimental reproducibility and application.

The procedure described in our article (Figure 1) is defined, efficient, highly reproducible and cost-effective, allowing the production of functional liver spheres, which remain functional over a year in vitro and provide critical liver support in vivo ${ }^{14}$. Importantly, this platform allows the user to control the size of the 3D liver spheres, limiting the formation of dense necrotic centers and loss of phenotype.

The transfer of the 3D hepatospheres to the poly-HEMA coated plates represents a critical step in this protocol. It is important to pipette gently at this stage in the procedure to avoid damaging the sphere. In addition, media changes must be performed carefully to avoid shear stress and distortion of sphere structure.

In these studies, 3D hepatospheres displayed an organized structure (Figure 2 and Figure 3), cytochrome P450 function (Figure 4) and secreted liver proteins, including albumin and alpha-fetoprotein (Figure 5). This procedure has been successfully performed in four pluripotent stem cells lines with comparable outcomes. Looking ahead, this technology could be employed as a platform to develop further endodermal and mesenchymal tissues with complex architectures.

\section{Disclosures}

David C. Hay is a co-founder and shareholder of Stemnovate Ltd and HigherSteaks Ltd. The rest of the authors certify that they have no conflicts of interest in the subject matter or materials discussed in this article.

\section{Acknowledgments}

This study was supported with awards from the UK Regenerative Medicine Platform (MRC MR/L022974/1) and the Chief Scientist's Office (TCS/16/37).

\section{References}

1. Hay, D.C., et al. Direct differentiation of human embryonic stem cells to hepatocyte-like cells exhibiting functional activities. Cloning and Stem Cells. 9 (1), 51-62 (2007).

2. Hay, D.C., et al. Highly efficient differentiation of hESCs to functional hepatic endoderm requires ActivinA and Wnt3a signaling. Proceedings of the National Academy of Sciences of the United States of America. 105 (34), 12301-12306 (2008).

3. Hay, D.C., et al. Efficient Differentiation of Hepatocytes from Human Embryonic Stem Cells Exhibiting Markers Recapitulating Liver Development In vivo. STEM CELLS. 26 (4), 894-902 (2008).

4. Hannan, N.R., Segeritz, C.-P., Touboul, T., Vallier, L. Production of hepatocyte like cells from human pluripotent stem cells. Nature protocols. 8 (2), 430-437 (2013).

5. Loh, K.M., et al. Efficient endoderm induction from human pluripotent stem cells by logically directing signals controlling lineage bifurcations. Cell Stem Cell. 14 (2), 237-252 (2014).

6. Sullivan, G.J., et al. Generation of Functional Human Hepatic Endoderm from Human iPS cells. Hepatology. 51 (1), $329-335$ (2010).

7. Si-Tayeb, K., et al. Highly Efficient Generation of Human Hepatocyte-like Cells from Induced Pluripotent Stem Cells. Hepatology. 51 (1), 297-305 (2010). 
8. Wang, Y., et al. Defined and Scalable Generation of Hepatocyte-like Cells from Human Pluripotent Stem Cells. Journal of Visualized Experiments. (121), (2017).

9. Meseguer-Ripolles, J., Lucendo-Villarin, B., Wang, Y., Hay, D.C. Semi-automated Production of Hepatocyte Like Cells from Pluripotent Stem Cells. Journal of Visualized Experiments. (137), (2018).

10. Cameron, K., et al. Recombinant Laminins Drive the Differentiation and Self-Organization of hESC-Derived Hepatocytes. Stem Cell Reports. 5 (6), 1250-1262 (2015).

11. Zhou, X., et al. Modulating Innate Immunity Improves Hepatitis C Virus Infection and Replication in Stem Cell-Derived Hepatocytes. Stem Cell Reports. 3 (1), 204-214 (2014).

12. Lyall, M.J., et al. Modelling non-alcoholic fatty liver disease in human hepatocyte-like cells. Philosophical Transactions of the Royal Society B: Biological Sciences. 373 (1750), 20170362 (2018).

13. Szkolnicka, D., et al. Reducing Hepatocyte Injury and Necrosis in Response to Paracetamol Using Noncoding RNAs. Stem Cells Translational Medicine. 5 (6), 764-772 (2016).

14. Lucendo-Villarin, B., et al. Modelling foetal exposure to maternal smoking using hepatoblasts from pluripotent stem cells. Archives of Toxicology. 91 (11), 3633-3643 (2017).

15. Rashid, S.T., et al. Modeling inherited metabolic disorders of the liver using human induced pluripotent stem cells. The Journal of Clinical Investigation. 120 (9), 3127-3136 (2010).

16. Godoy, P., et al. Gene networks and transcription factor motifs defining the differentiation of stem cells into hepatocyte-like cells. Journal of Hepatology. 63 (4), 934-942 (2015).

17. Lucendo-Villarin, B., Rashidi, H., Cameron, K., Hay, D.C. Pluripotent stem cell derived hepatocytes: using materials to define cellular differentiation and tissue engineering. Journal of Materials Chemistry B, Materials for Biology and Medicine. 4 (20), 3433-3442 (2016).

18. Fang, Y., Eglen, R.M. Three-Dimensional Cell Cultures in Drug Discovery and Development. Slas Discovery. 22 (5), 456-472 (2017).

19. Edmondson, R., Broglie, J.J., Adcock, A.F., Yang, L. Three-Dimensional Cell Culture Systems and Their Applications in Drug Discovery and Cell-Based Biosensors. Assay and Drug Development Technologies. 12 (4), 207-218 (2014).

20. Gieseck, R.L., et al. Maturation of Induced Pluripotent Stem Cell Derived Hepatocytes by 3D-Culture. PLoS ONE. 9 (1), (2014).

21. Takebe, T., et al. Generation of a vascularized and functional human liver from an iPSC-derived organ bud transplant. Nature Protocols. 9 (2), 396-409 (2014).

22. Camp, J.G., et al. Multilineage communication regulates human liver bud development from pluripotency. Nature. 546 (7659), 533-538 (2017).

23. Rashidi, H., et al. 3D human hepatospheres from pluripotent stem cells displays stable phenotype in vitro and supports compromised liver function in vivo. Archives of Toxicology. 92 (10), 3117-3129 (2018).

24. Takebe, T., et al. Massive and Reproducible Production of Liver Buds Entirely from Human Pluripotent Stem Cells. Cell Reports. 21 (10), 2661-2670 (2017). 